\title{
RESULTS OF INTRAOCULAR LENS IMPLANTATION IN PAEDIATRIC APHAKIA
}

\author{
R. H. C. MARKHAM, P. A. BLOOM, A. CHANDNA, E. H. NEWCOMB \\ Bristol
}

\begin{abstract}
SUMMARY
Intraocular lenses were implanted in 16 eyes of 13 patients with congenital cataract, and visual progress was plotted using a preferential-looking technique. Initial surgery was by lens aspiration with preservation of the posterior capsule, and subsequent posterior capsulotomy without anterior vitrectomy. Poly-HEMA posterior chamber lenses were used, usually as a primary procedure but in four cases as a secondary procedure after contact lens failure. No serious complications were encountered. Most eyes achieved a very significant visual improvement, and none were worse than preoperatively. Residual refractive error was highly unpredictable, but did not exceed 6 dioptres. The importance of rigorous occlusion therapy is stressed. With close follow-up, this procedure offers an effective and safe method for the correction of unilateral paediatric aphakia, and, in selected cases only, for bilateral aphakia.
\end{abstract}

Unilateral congenital cataract has long been regarded as a condition with a poor visual prognosis. ${ }^{15}$ This is not because cataract aspiration is difficult-modern instrumentation has made this relatively straightforward-but because of the problems of treatment of the accompanying dense amblyopia. Where significant unilateral cataract is present from birth, clarity of the media and correction of the induced high hypermetropia must be established at a very early age, ${ }^{6}$ and it is the latter problem that is so difficult to overcome.

Aphakic spectacles might be adequate while the good eye is being occluded, but are rarely satisfactory, because of image size difference, when the patch is off, allowing any improvement in amblyopia to slip back. ${ }^{7}$

Contact lenses have been the standard method of correction, but while good results have been reported by some, ${ }^{811}$ most have found the level of vision achieved to be a poor reward for all the time, effort, expense, and trauma of repeated contact lens fittings affecting patient, parent, and clinic staff alike. ${ }^{12,13}$ There is also the problem

From: Bristol Eye Hospital, Lower Maudlin Street, Bristol BS I 2LX.

Correspondence to: Mr R. H. C. Markham, Bristol Eye Hospital, Lower Maudlin Street, Bristol BSI 2LX. of residual image size difference between the two eyes even with contact lenses, possibly contributing to image suppression in the aphakic eye between periods of patching, ${ }^{14}$ and also the suspicion that repeated attention to the contact lens makes patching more difficult to administer.

Epikeratophakia may offer another form of optical correction to the older aphakic child, ${ }^{15}$ but at present is not widely available, and is expensive. In addition, the procedure may not allow a clear visual axis early enough for infants with congenital cataract, due to corneal haze which is often slow to clear.

Intraocular lens implantation avoids many of these difficulties, while potentially adding some of its own. ${ }^{7.12 .16-20}$ The change in refraction seen over the first two years or so of a child's life-usually a loss of several dioptres of hypermetropia-have suggested to some that an intraocular lens might need replacement at least once in a lifetime to keep up with this change; full correction from the start would lead to marked overcorrection later. ${ }^{8}$ Also, although there is now forty years' experience with PMMA as an intraocular material, this is perhaps only half a child's expected lifetime, and PMMA itself is probably not the most suitable lens material for an infant's eye, because a rigid lens may be more difficult to introduce and could damage corneal endothelial cells by direct contact. There is even shorter experience with other lens materials. ${ }^{21}$

All methods of correction of aphakia have the disadvantage that whereas there may be some depth of focus, they cannot compete with the large focusing range of the good eye.

Despite these problems, we felt that the theoretical advantages of intraocular lens implantation were very great, and the theoretical disadvantages could be overcome. The traditionally poor visual prognosis in unilateral congenital cataract calls for new approaches in this important cause of childhood ocular morbidity. If safety of implantation can be shown in this group, the technique can be extended to bilateral cataracts which traditionally have a better visual prognosis. ${ }^{22}$

Experience with the later development of retinal 
detachment after adult intracapsular cataract extraction, extracapsular cataract extraction and capsulotomy in the absence of an intraocular lens, and after older methods of congenital cataract removal, ${ }^{23-25}$ made us think that there might be some merit in preserving the integrity of the posterior lens capsule and anterior vitreous. This view is reinforced by a reported incidence of aphakic cystoid macular oedema after lensectomy and anterior vitrectomy for congenital cataract. ${ }^{26} \mathrm{~A}$ posterior capsulotomy should perhaps only be carried out if, at the end of the operation for lens aspiration and implantation, central posterior capsular opacities could not be polished away, or if the capsule thickened up postoperatively.

The utilisation of forced choice preferential looking (FCPL) tehniques using Teller Acuity Cards in our unit has proved a powerful and accurate tool both in the preoperative assessment of visual acuity in infants with congenital cataract and in monitoring their subsequent progress. $^{27,28}$

We therefore report the results of a method of intraocular lens implantation in a group of children with congenital cataract, unilateral in all but four subjects, and their subsequent progress closely followed by FCPL visual assessment. We used lens aspiration without primary capsulotomy in most cases, and poly-HEMA intraocular lenses in all but one case. All are being kept under longterm surveillance.

\section{MATERIALS AND METHODS}

Six patients with unilateral congenital cataract underwent lens aspiration and primary intraocular lens implantation (eyes a, b, c, e, k, n). Two additional patients with unilateral congenital cataract originally undergoing lens aspiration alone, had secondary intraocular lens implants after contact lens failure (eyes $1, \mathrm{~m}$ ). In one other patient, spontaneous reabsorption of a unilateral cataract occurred and was followed by a secondary intraocular lens implant in this eye (eye $d$ ).

Four further patients had bilateral congenital cataracts. Of these, two had primary intraocular lens implantation in both eyes from the start (eyes $\mathrm{f}, \mathrm{g}, \mathrm{o}, \mathrm{p}$ ), one had primary intraocular lens implantation in one eye and a secondary intraocular lens implant in the other eye after contact lens failure (eyes i, j), and one, with Down's Syndrome, had a primary intraocular lens implant in one eye and elective use of a contact lens in the other (eye h).

Thus, in total, there were sixteen intraocular lens implants in thirteen patients (Table I).

Before intraocular lens implantation in any eye, the possible treatment options and the investigational nature of the procedure with its advantages and disadvantages were fully discussed with the parents.

Apart from cataract, convergent squint was present in one child preoperatively (eye k). There was no other ocular abnormality detected in any case. Aetiology was generally unknown, except that one patient with bilateral cataracts had a family history of dominantly inherited cataract (eyes f, g), one child suffered from Alagille's Syndrome (eye k), and one from Down's Syndrome (eye h) (Table I).

Preoperatively, an attempt was made to measure visual acuity formally in all cases. According to age, methods used were Forced Choice Preferential Looking (FCPL) using Teller Acuity Cards, Kay Pictures, Sheridan-Gardiner, or Snellen.

Age at original surgery varied from three to 57 months for primary intraocular lens implants (eyes a, b, c, e, f, g, h, i), and from three to 88 months for secondary lens implants (eyes d, j, l, m). One child listed as a secondary implant had spontaneous reabsorption of dense cataract and therefore needed no primary operation (eye d) (Table I).

Surgery consisted of lens aspiration using a vitreous suction cutter through a limbal 20 gauge entry site and a small anterior lens capsular opening. A second entry site, $180^{\circ}$ opposite, was occupied by a 20 gauge cannula infusing Balanced Salt Solution (Alcon). The suction cutter and infusion could be swapped round at will to gain easy access to all parts of the capsular bag. Most of the work was carried out using aspiration alone.

At the end of this stage, the anterior capsular opening was enlarged using the cutting facility of the suction cutter

Table I. Details of aphakic children treated by IOL implantation. (Note that subject indexes $f \& g$, $i$ \& $j$ and o \& p refer to two eyes of the same patient)

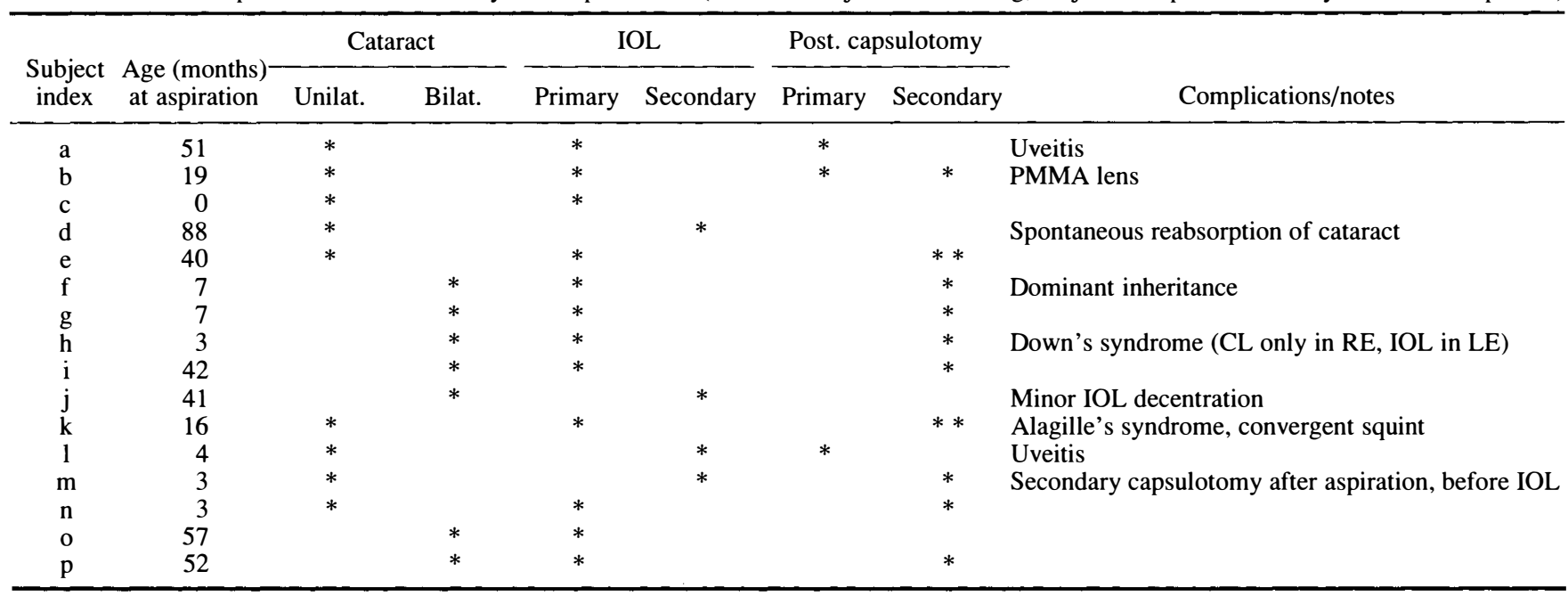


instrument. The posterior lens capsule and anterior vitreous were preserved, save in three cases where a primary capsulotomy was carried out, without anterior vitrectomy, after lens implantation. In two children this was performed via a separate pars plana sclerotomy (eyes a, l), and in the other child, through the cornea and behind the only PMMA lens that was used in the study (eye b).

One corneal entry site was then sealed with a 10/0 nylon suture, leaving the infusion in situ, and a shelving $7 \mathrm{~mm}$ superior corneal limbal incision made to introduce the intraocular lens. We used Alcon Iogel poly-HEMA posterior chamber intraocular lenses in all except one case, mostly $11.3 \mathrm{~mm}$ diameter but one $10.3 \mathrm{~mm}$ diameter (eye n). The one exception had a $14 \mathrm{~mm}$ diameter Sinskey pattern PMMA posterior chamber lens with polypropylene loops made by Allergan Medical Optics (eye b).

At the end of the operation, subconjunctival gentamicin $(0.4 \mathrm{mg} / \mathrm{kg}$ body weight) and a depot preparation of methylprednisolone (Depomedrone, Upjohn, $0.4 \mathrm{mg} / \mathrm{kg}$ body weight) was given. Postoperatively, parents were instructed to give prednisolone acetate 1\% (Pred Forte, Allergen), and fucidic acid $1 \%$ slow release eye drops (Fucithalmic, Leo) twice a day, for approximately three weeks until the eye settled. The pupils were not kept dilated.

Follow-up was carried out at weekly, then monthly, and subsequently greater intervals depending on progress and age of child, and an attempt was made to measure visual acuity assessed on each occasion by the most appropriate method for the age of the child (FCPL, Kay Pictures, Sheridan-Gardiner, Snellen), but always including FCPL.

Secondary posterior capsulotomy, where required, was carried out via a pars plana incision using a vitreous suction cutter, and with an anterior chamber infusion of Balanced Salt Solution via the cornea, as in the primary capsulotomies. No attempt was made to carry out an anterior vitrectomy.

\section{RESULTS}

There were no serious intraoperative or postoperative complications. Postoperative fibrinous uveitis responded rapidly to conventional treatment in two eyes (eyes a, m). Minor decentration occurred in one lens but is not considered visually significant (eye j) (Table I).

Thickening of the posterior lens capsule occurred between one month and two years in nine of the thirteen eyes that had not had a primary posterior capsulotomy. In infants, this was often indicated by a drop in acuity measured by FCPL of more than half an octave, that is, more than one Teller Acuity Card (approximately equivalent to more than one line of Snellen acuity). However, four eyes have not developed posterior capsular thickening to date (eyes c, d, j, o). Two eyes required one repeat posterior capsulotomy (eyes e, $\mathrm{k}$ ); all had been secondary capsulotomies the first time round, and possibly inadequate in size from the beginning (Table I).

A variety of methods was used to assess visual acuity preoperatively according to age, as follows:

$\begin{array}{ll}\text { FCPL } & \text { Eyes b, c, f, g, i, j, n, o, p } \\ \text { Kay Pictures } & \text { Eyes i, j, o } \\ \text { Sheridan-Gardiner } & \text { Eye e } \\ \text { Snellen } & \text { Eye d }\end{array}$

In five children no preoperative acuity could be recorded, three of these associated with total cataract (eyes $\mathrm{a}, \mathrm{k}, \mathrm{l}, \mathrm{m}, \mathrm{n})$. Finally, no attempt was made to formally test the acuity of one premature infant with Down's Syndrome and bilateral dense cataract (eye h). In these six children, the denseness of the cataracts made it reasonable to assume that the eyes were effectively blind, and that in the five eyes where testing produced no result, this was because of blindness rather than technical problems.

By contrast, a postoperative FCPL acuity was recorded on every child at some stage (this may partly have reflected our increasing skills with this technique). Where possible without loss of accuracy, all acuity measurements were converted to Snellen equivalents for ease of comparison. It has to be appreciated that these can only be approximate conversions. In cases where both FCPL and Snellen acuities had been recorded at the same time, there was usually remarkable correspondence between the two.

Preoperative, best postoperative, and latest recorded

Table II. Visual acuity before and after IOL implantation for paediatric aphakia

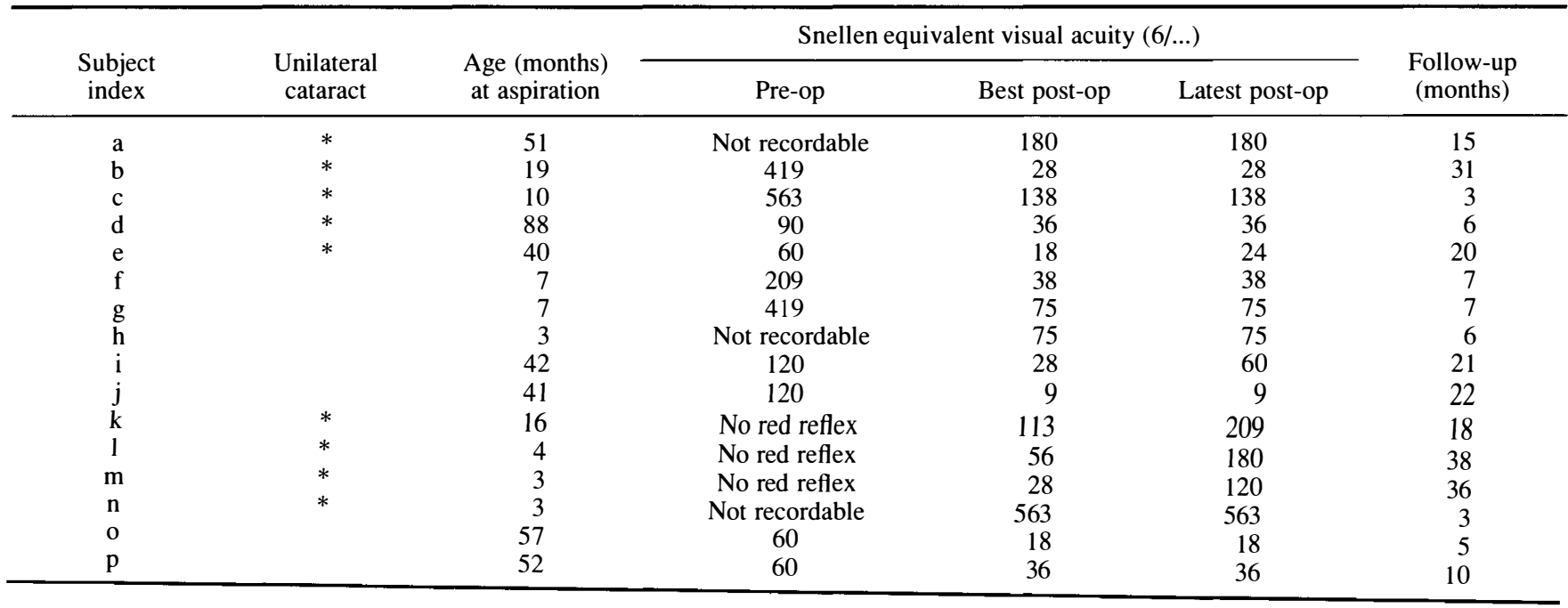


Table III. Additional procedures after IOL implantation for paediatric aphakia

\begin{tabular}{|c|c|c|c|c|c|c|}
\hline $\begin{array}{l}\text { Subject } \\
\text { index }\end{array}$ & $\begin{array}{l}\text { EUA/ } \\
\text { refraction }\end{array}$ & $\begin{array}{l}\text { Secondary } \\
\text { post. } \\
\text { capsulotomy }\end{array}$ & $\begin{array}{c}\text { Removal } \\
\text { of } \\
\text { sutures }\end{array}$ & $\begin{array}{l}\text { Freeing. } \\
\text { of } \\
\text { synechiae }\end{array}$ & $\begin{array}{l}\text { Squint } \\
\text { op. }\end{array}$ & $\begin{array}{c}\text { Total no. } \\
\text { additional } \\
\text { GAs }\end{array}$ \\
\hline a & * & & * & & & 1 \\
\hline b & & * & * & & & 2 \\
\hline $\mathrm{c}$ & $*$ & & * & & & 1 \\
\hline d & & & & & & () \\
\hline $\mathrm{e}$ & * & $* *$ & & $*$ & & 2 \\
\hline f & & $*$ & & & & 1 \\
\hline $\mathrm{g}$ & & * & & & & 1 \\
\hline $\mathrm{h}$ & & * & & * & & 1 \\
\hline $\mathrm{i}$ & & * & * & & & 2 \\
\hline $\mathrm{j}$ & & & & & & 0 \\
\hline$\hat{k}$ & * & $* *$ & & * & * & 2 \\
\hline 1 & * & & & & & 1 \\
\hline $\mathrm{m}$ & & & & & & () \\
\hline $\mathrm{n}$ & & * & & & & 1 \\
\hline o & & & & & & () \\
\hline $\mathrm{p}$ & & * & & & & 1 \\
\hline
\end{tabular}

visual acuities were then compared. No postoperative best or latest acuity was worse than preoperatively, and most were very significantly improved (Table II; Figs. 1 \& 2).

Comparisons between preoperative and best postoperative acuity estimates and, for further comparison, preoperative and latest visit acuity estimates were treated as paired data. To determine whether surgical intervention and postoperative treatment had made any significant impact on improvement in acuity, the difference between the two sets of paired data for the affected eyes were calculated in octave units. (An octave is a doubling or halving of the spatial frequency; for example, the difference between 15 and 30 cycles/degree or, in approximate Snellen equivalent terms, the interval between 6/12 and 6/6.) $\mathrm{A}$ Wilcoxon signed ranks test on the differences revealed a highly significant improvement in acuity from the preoperative visual status for both the best achieved acuity ( $p$ $=0.001$, median improvement 2.27 octaves [approx. 4 Snellen lines], 95\% CI [1.69, 2.89]), and the latest,visit acuity $(\mathrm{p}=0.001$, median improvement 1.83 octaves [approx. 3 Snellen lines], 95\% CI [1.32, 2.28]). The marginal decrease in median improvement for the latest visit acuity is probably due to a premature relaxation in the occlusion regime-a drop which we would hope to reverse.

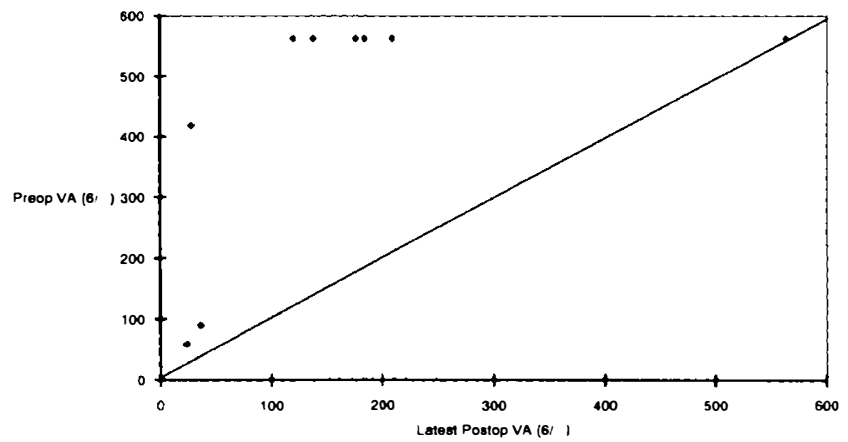

Fig. 1. Graph comparing preoperative Snellen equiralent visual acuity (VA) with best recorded postoperative VA following IOL implantation for paediatric aphakia.
Table IV. Residual mean spherical refractive error following IOL implantation for paediatric aphakia

\begin{tabular}{ccc}
\hline $\begin{array}{c}\text { Subject } \\
\text { index }\end{array}$ & $\begin{array}{c}\text { IOL } \\
\text { power }\end{array}$ & $\begin{array}{c}\text { Post-op } \\
\text { refraction }\end{array}$ \\
\hline a & 23.5 & +6.00 \\
b & 24.0 & -4.00 \\
$\mathrm{c}$ & 25.0 & +6.00 \\
$\mathrm{~d}$ & 25.0 & +0.50 \\
$\mathrm{e}$ & 22.5 & +1.00 \\
$\mathrm{f}$ & 23.0 & Plano \\
$\mathrm{g}$ & 23.0 & +0.75 \\
$\mathrm{~h}$ & 24.0 & Plano (?) \\
$\mathrm{i}$ & 23.5 & +1.25 \\
$\mathrm{j}$ & 23.5 & +0.75 \\
$\mathrm{k}$ & 26.0 & -3.00 \\
$\mathrm{l}$ & 24.0 & -4.00 \\
$\mathrm{~m}$ & 26.0 & +4.00 \\
$\mathrm{n}$ & 24.0 & +3.00 \\
$\mathrm{o}$ & 22.0 & -5.50 \\
$\mathrm{p}$ & 22.5 & -2.50 \\
\hline
\end{tabular}

Additional general anaesthetics after lens implantation were required in some children for examination or further procedures such as secondary posterior capsulotomy, freeing of anterior synechiae, removal of sutures, or squint correction (Table III). These procedures were often combined during one anaesthetic. No child had more than two additional anaesthetics, and four children have needed no additional anaesthetics to date (eyes $\mathrm{d}, \mathrm{j}, \mathrm{m}, \mathrm{o}, \mathrm{p}$ ).

Residual postoperative refractive error and the power of the intraocular lens are shown in Table IV. It can be seen that even when lens aspiration and implantation was carried out at three months of age, the residual error could easily be corrected by glasses, or a temporary low power contact lens in one case (eye $n$ ). We found the maximum overcorrection to be less than we had anticipated before the study started, and also to be surprisingly unpredictable in value.

\section{DISCUSSION}

If intraocular lens implantation for the correction of aphakia after aspiration of congenital cataracts can be shown to be as effective and safe a method as it is in adult aphakia, the management of congenital cataract will become very much simpler, allowing our efforts to be directed to the relief of the other major problem-amblyopia.

$$
\text { - Unilateral Canaract Bulateral Cataract }
$$

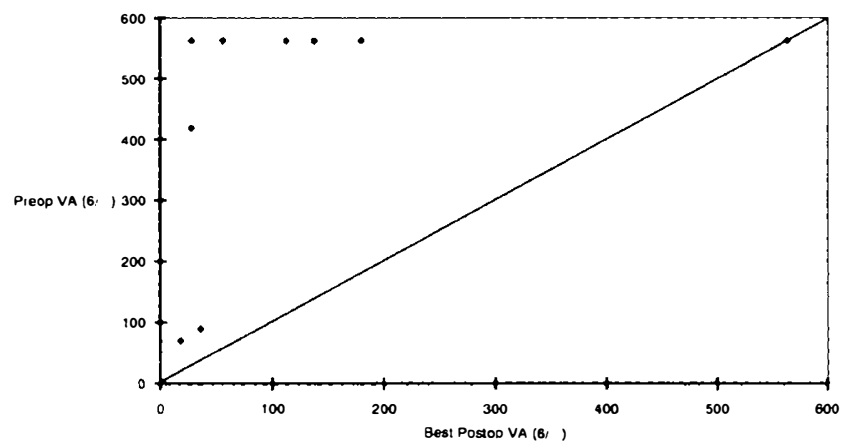

Fig. 2. Graph comparing preoperative Snellen equiralent visual acuity (VA) with latest recorded postoperative VA following IOL implantation for paediatric aphakia. 
For the most part, our study concerned the management of unilateral congenital cataract, and it seems reasonable at this stage to limit intraocular lens implantation to unilateral cases, which have a poor visual prognosis, until longer follow-up has definitely established the safety of this tehnique and favourable long-term visual results. The technique can then be extended to the category of bilateral cataract which has a better visual prognosis. ${ }^{4}$ However, where it is believed that neither glasses nor contact lenses will prove to be a satisfactory method for correction of bilateral aphakia, bilateral intraocular lens implantation should in our opinion be considered now.

We identified and addressed potential problems in six areas in this study.

\section{(1) Suitable intraocular lens material}

Poly-HEMA as a lens material has the advantage that inflammatory cells are not readily deposited on the anterior or posterior surface. ${ }^{29}$ This is important since anterior uveitis is the most commonly reported complication in our and other reported studies, ${ }^{7.16 .30 .31}$ particularly if there has been any manipulation of the iris.

So far, there has been no reason to doubt the biocompatibility of this material in the intraocular situation.

\section{(2) Lens design and method of intraocular fixation}

We used Iogel 1103 lenses except in two eyes. One had the smaller diameter Iogel 1003 pattern. There appeared to be no difference between the two Iogel lenses. One other child had a PMMA lens (Allergan Medical Optics) which was quite satisfactory but these lenses might be difficult to manoeuvre in an infant eye.

The poly-HEMA lenses are easy to insert through a shelving corneal incision without loss of the anterior chamber depth even without the use of a viscoelastic substance. No attempt was made to insert the lens into the capsular bag for three reasons. First, it is very difficult to insert any lens into the capsular bag in children because the two leaves are usually pressed tightly together requiring excessive manipulation that in children often leads to a marked fibrinous uveitis. ${ }^{7}$ Secondly, allowing the anterior and posterior leaves of the lens capsule to adhere behind the intraocular lens means that after a subsequent posterior capsulotomy the size of the gap is limited, very much reducing the possibility of posterior dislocation of the lens into the vitreous cavity-otherwise a potential problem with these lenses. ${ }^{29}$ Finally, capsular fixation can result in marked decentration of a soft intraocular lens from unequal contraction of the capsular bag. This is particularly so if one flange of the lens is in the bag and one in the sulcus. $^{29}$

The apparent marked bicompatibility of the polyHEMA material means that no tissue reaction develops to hold the lens firmly in place as in PMMA lenses. This probably contributed to the slight decentration observed in two of our lenses. If any lens had to be removed subsequently, this would clearly become an advantage.

\section{(3) Intraocular lens power}

One of the criticisms of intraocular lens implantation in infants is that hypermetropia decreases markedly over the first two years of life in most children, and therefore the required full correction of aphakia at three months of age is likely to be a marked overcorrection at two years. ${ }^{32} \mathrm{We}$ aimed to manage this problem by implanting lenses of a power that we estimated would subsequently give a refraction of approximately -2.00 dioptres in later life. In infants, this would leave residual hypermetropia that could be corrected with glasses or a low power contact lens which is easy to manage compared with a full aphakic contact lens. It was never our intention to change the intraocular lens at any stage, and, as can be seen from our results, residual refractive error did not seem to be a major problem (Table IV). Toward the end of the study we began to carry out biometry and keratometry in order to gauge suitable intraocular lens power with more accuracy immediately preoperatively; in practice, this did not seem to decrease the postoperative residual error, but merits more detailed study in future cases.

\section{(4) Treatment of amblyopia}

All unilateral and some bilateral congenital cataracts will have dense amblyopia requiring occlusion or penalisation therapy. We aimed to carry out total occlusion of the good eye for eight hours daily starting within one week of lens aspiration, and lasting for a period depending on response to treatment. We anticipated that this treatment might be more readily accepted by child and parents if they did not have to manage an aphakic contact lens at the same time. We cannot say whether this is true at the present stage.

In retrospect, we feel that our occlusion regime was not adequate in practice, probably resulting in poorer visual results than could otherwise have been obtained. We hope to remedy this in future cases, believing that parents need to know exactly what regime and targets are planned, so that they can in turn give their full co-operation.

\section{(5) Measurement of visual acuity}

In order to follow progress in amblyopia treatment, and recognise problems such as posterior capsular thickening in the youngest patients, we needed a reliable system of visual acuity measurement in this age group. The utilisation of the Forced Choice Preferential Looking method of visual acuity assessment in this unit has fulfilled this role where previously no accurate method existed for this age group. ${ }^{28}$ Not all children were assessed by FCPL preoperatively because our system was not fully developed at that stage. Preoperative visual acuity in some children was too poor to allow a response to any method of testing.

All children were assessed postoperatively by FCPL however, and some by other standard methods such as Kay Pictures, Sheridan-Gardiner, and Snellen, in order to cross-check reliability. Where comparisons between FCPL and the other standard methods were possible, there was remarkable consistency between the two.

(6) Method of posterior capsulotomy

We felt that in order to minimise the possibility of 
development of retinal detachment in later years, there should be the minimum of disturbance of the anterior vitreous body. Thickening of the posterior lens capsule is very frequent after lens aspiration in children. ${ }^{16}$ Posterior capsulotomy through the cornea before or at the time of lens implantation in children usually results in the formation of vitreous strands to the corneal entry site unless an anterior vitrectomy is carried out. ${ }^{7,12}$

We therefore elected to carry out secondary posterior capsulotomies only when the capsule developed thickening (shown in some infants by a drop in FCPL acuity), or primary capsulotomies if posterior capsular opacities could not be polished away at the time of lens aspiration. We used a vitreous suction cutter introduced via the pars plana and with an anterior chamber infusion of Balanced Salt Solution through the peripheral cornea. Even then, only posterior lens capsule was removed and no attempt made to carry out an anterior vitrectomy. It is likely that a suitably mounted Neodymium YAG laser would make posterior capsulotomy an even easier and safer procedure. One of our children had a prmary capsulotomy after implantation of the only PMMA lens. This was carried out through the cornea and is easier with this pattern of rigid lens but still runs risks of vitreous incarceration into the corneal entry site.

We believe that recent work, ${ }^{12,21}$ including our own, shows that we are already a considerable way along the path of safe intraocular lens implantation in children. Close and continued follow-up of implanted eyes will be essential, but we feel confident that this will prove to be an ideal method of unilateral aphakic correction, extendable to bilateral cases as experience develops.

Key words: Amblyopia, Congenital cataract, Intraocular lenses, PolyHEMA lenses, Preferential looking, Residual refraction.

\section{REFERENCES}

1. Costenbander FD, Albert DG: Conservatism in the management of congenital cataracts. Arch Ophthalmol 1957, 58: 426-30.

2. Parkes MM, Hiles DA: Management of infantile cataracts. Am J Ophthalmol 1967, 63: 10-19.

3. Dahan E, Salmenson BD: Pseudophakia in children: Precautions, technique and feasibility. J Cataract Refract Surg 1990, 16: 75-82.

4. D'Esposito M, Magli A, Daniele A: Functional recovery in paediatric cataract. Eur J Implant Ref Surg 1990, 2: 262-4.

5. Davies PD, Tarbuck DTH: Management of cataracts in infancy and childhood. Trans Ophthalmol Soc UK 1977, 97: 148-52.

6. Vaegan J, Taylor D: Critical period for deprivation amblyopia in children. Trans Ophthalmol Soc UK 1980, 99: 432-9.

7. Hiles DA: Visual rehabilitation of aphakic children: III. Intraocular lenses. Surv Ophthalmol 1990, 34: 371-9.

8. Holmstrom G, Speedwell L, Taylor D: Contact lenses-still the only solution for infant aphakia. Eur J Implant Ref Surg 1990, 2: 265-7.

9. Levin AV, Edmonds SA, Nelson LB, Calhoun JH, Harley RD: Extended-wear contact lens for the treatment of pediatric aphakia. Ophthalmology 1988, 95: 1107-13.
10. Beller R, Hoyt CS, Marg E, Odom JV: Good visual function after neonatal surgery for congenital monocular cataracts. Am J Ophthalmol 1981, 91: 559-65.

11. Pratt-Johnson JA, Tillson G: Hard contact lenses in the management of congenital cataract. J Pediat Ophthalmol \& Strab 1985, 22: 94-6.

12. Dahan E, Welsh NH, Salmenson BD: Posterior chamber implants in unilateral congenital and developmental cataracts. Eur J Implant Ref Surg 1990, 2: 295-302.

13. Benezra D, Rose L: Intraocular versus contact lenses for the correction of aphakia in unilateral congenital and developmental cataract. Eur J Implant Ref Surg 1990, 2: 303-7.

14. Katsumi O, Miyanaga Y, Hirose T, Okuno H, Asaoka I: Binocular function in unilateral aphakia. Ophthalmology 1988, 95: 1088-93.

15. Uusitalo RJ: Epikeratophakia for correction of refractive error after unilateral congenital cataract extraction. Eur $J$ Refract Surg 1990, 2: 333-9.

16. Burke JP, Willshaw HE, Young JDH: Intraocular lens implants for uniocular cataracts in childhood. BrJ Ophthalmol 1989, 73: 860-4.

17. Hiles DA, Hered RW: Modern intraocular lens implants in children with new age limitations. J Cataract Refract Surg 1987, 13: 493-7.

18. Hiles DA, Cheng KP, Biglan AW: Aphakic optical correcttion with intraocular lenses for children with traumatic cataracts. Eur J Implant Ref Surg 1990, 2: 276-83.

19. Benezra D: Intraocular lenses for unilateral paediatric aphakia. Early lenses and long-term follow up. Eur J Implant Ref Surg 1990, 2: 285-9.

20. Yamamoto M: Long term prognosis of intraocular lens implantation in children. Eur J Implant Ref Surg 1990, 2: 291-3.

21. de Courten C, Bucher PJM, Benezra D: Experience with HEMA lenses in paediatric cataract. Eur J Implant Ref Surg 1990, 2: 315-8.

22. Gelbert SS, Hoyt CS, Jastrebski G, Marg E: Long term visual results in bilateral congenital cataracts. Am J Ophthalmol 1982, 93: 615-21.

23. Kanski JJ, Elkington AR, Daniel R: Retinal detachment after congenital cataract surgery. Br J Ophthalmol 1974, 58: 92-5.

24. Keech RV, Tongue AC, Scott WE: Complications after surgery for congenital and infantile cataracts. Am J Ophthalmol 1989, 108: 136-41.

25. Winshaw RL, Tasman W: Juvenile rhegmatogenous retinal detachment. Ophthalmology 1978, 85: 607-18.

26. Hoyt CS, Nickel B: Aphakic cystoid macular edema. Arch Ophthalmol 1982, 100: 746-9.

27. Chandna A: Natural history of the development of visual acuity in infants. Eye 1991, 5: 20-6.

28. Chandna A, Doran RML: Observations on grating acuity measures of children in clinical practice using Teller Acuity Cards. In Campos EC ed. Strabismus and ocular motility disorders. London: Macmillan Press, 1990: 85-94.

29. Barrett GD, Beasley H, Lorenzetti OJ, Rosenthal A: Multicenter trial of an intraocular hydrogel lens implant. J Cataract Refract Surg 1987, 13: 621-6.

30. Rich WJ, Condon PI, Percival SPB: Hydrogel intraocular lens experience with endocapsular implantation. Eye 1988, 2: 523-8.

31. Bucher PJM, Schimmelpfennig B, Faggini R: One year follow-up of Iogel intraocular lenses with ciliary sulcus fixation. J Cataract Refract Surg 1989, 15: 635-9.

32. Schulz E: Visual development and refractive changes in congenital cataract. Eur J Implant Ref Surg 1990, 2: 253-6. 